\title{
The Apparent Structure of the magnetic anomalies occurring in Bateke Plateau/Kinshasa-Democratic Republic of Congo
}

\author{
1 \\ 1 \\ 1 \\ 1 \\ Matadi Ndombasi Jonathan , Bakamubia Kanyinda , Makangila Ntimansiemi , Nzuzi Kudiayimbu , \\ Puati Puati Daddy and Maneno saidi \\ Research Scholar ${ }^{1}$ \\ Research Center of Geophysics (Centre de Recherche en Géophysique-CRG), Kinshasa \\ Democratic Republic of Congo \\ Research Scholar ${ }^{2}$ \\ Mining and Geological Research Center (Centre de Recherche Géologique et Minier- C.R.G.M), Kinshasa \\ Democratic Republic of Congo

\begin{abstract}
The magnetic field in the Bateke plateau has been observed using a proton magnetometer. The survey was made during the period from June to October 2015. The aim of the study is to determine the magnetic anomalies of this area. The observations were extended in the area planning from latitude $04^{\circ} 16^{\prime} 40^{\prime} \mathrm{S}$ to longitude $16^{\circ} 42^{\prime} 30 \mathrm{~W}$. While the geological structure of this area presents quite smooth variations, the geomagnetic distribution shows some irregularities associated with moho structure of this zone.
\end{abstract}

Keywords: Magnetic anomaly, Total magnétic field, Density.

\section{INTRODUCTION}

The earth's magnetic field resembles the field of a large bar magnet near its center or that due to uniformity magnetized sphere. The origin of the field is not well understood, but thought to be due to currents in a fluid conductive core. On the surface of the earth the pole of this equivalent bar magnetic pole, the north geographical pole, is actually a" south" magnetic pole. This paradoxical situation exists since by convention a north seeking end of a compass needle is defined as pointing north yet must point to a pole of opposite sense or South Pole of the earth's magnetic field. To avoid possible confusion, though, the magnetic pole near the geographical North Pole is, and will be referred to as, "north" pole [2].

City of Kinshasa is constituted with the actual city and rural part, the rural part is composed with $75 \%$ of Kinshasa city. The «Bateke plateau » is stands on this rural part and Two mains rivers, Mayi-Ndombe and Lufimi run accross Bateke plateau (Figure 1). 


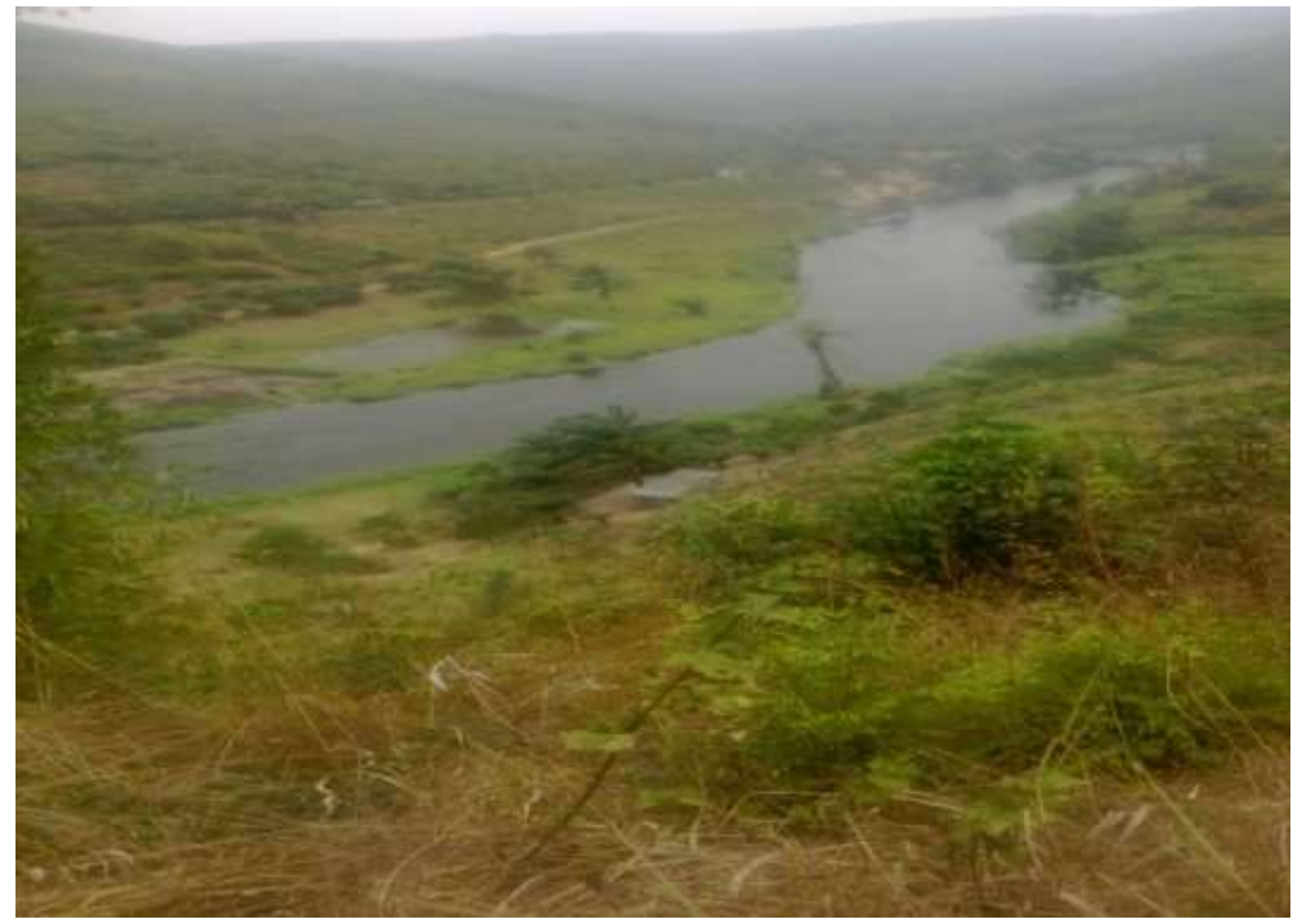

Figure 1: Mayi-ndombe river presentation

With the project to establish the magnetic maps in the west part of Kinshasa ,The CRG began the magnetic measurements harvest in Kinshasa and it will be extended to others provinces such as: Kongo-central, Kwango and Kwilu,The reason is to facilitate the initiation of more reaserchers.

\section{STUDY AREA PRESENTATION}

Bateke plateau covers an area of $7500 \mathrm{Km}^{2}$ and the vegetations in this area are zambezian steppe of kalaharian sand and mosaic region. The Figure.2 describes the Bateke plateau [3].

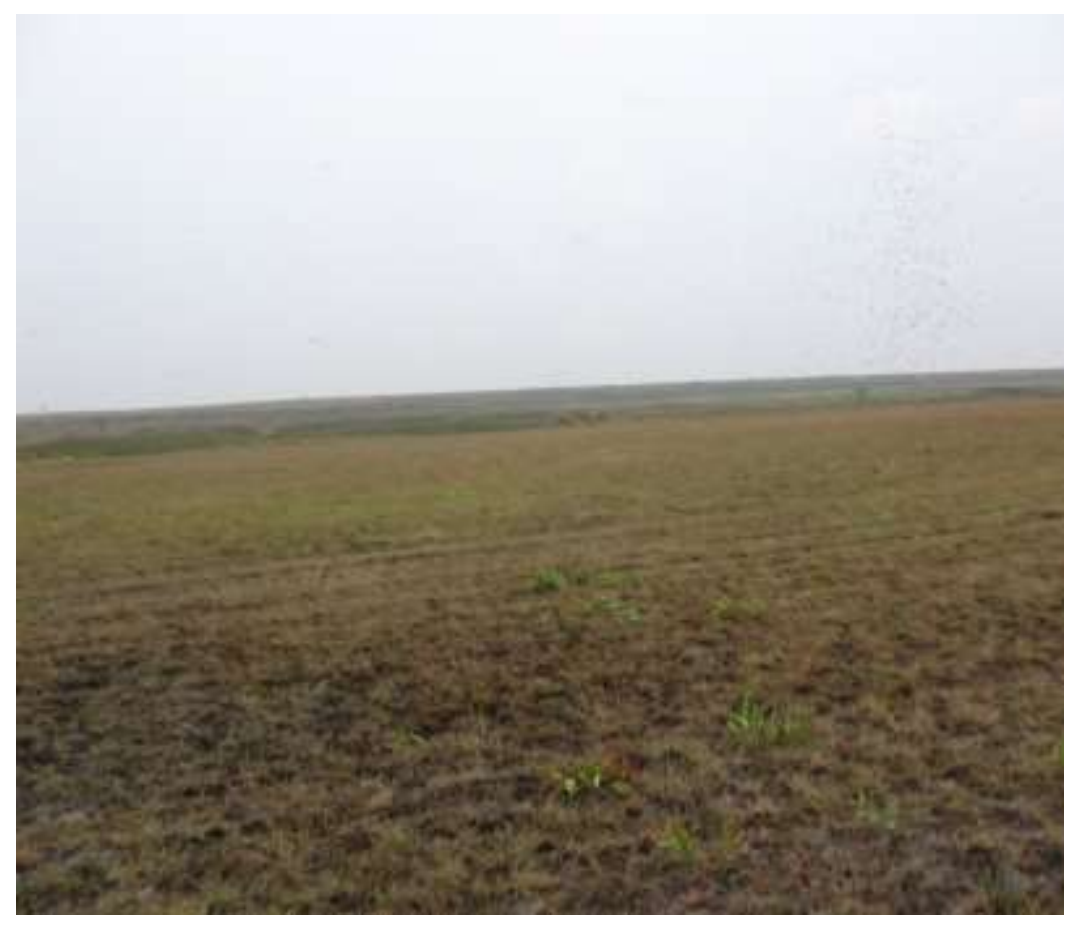

Figure 2: View of Bateke plateau 
The investigation region is limited in the west meridian $16^{\circ} 10^{\prime} 22^{\prime \prime}$ longitude East ; North by the parallel $4^{\circ} 11^{\prime}$ $11.41^{\prime \prime}$ latitude South and to south by the parallel $4^{\circ} 37^{\prime} 24.4^{\prime \prime}$ latitude South(Figure 3).

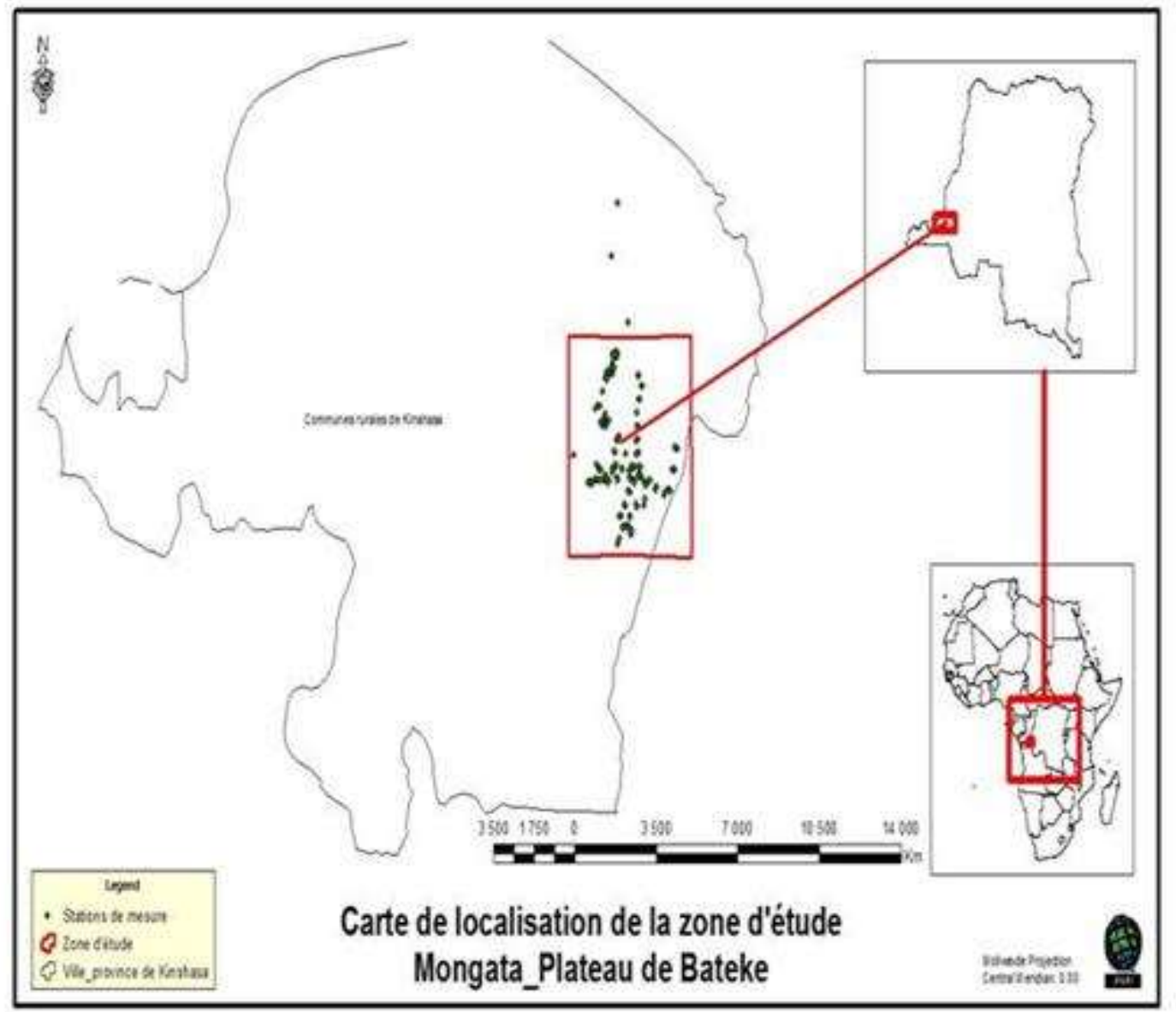

Figure 3: The study area presentation

\section{DATA AND METHOD}

Geomagnetic method was made in the survey by using a portable proton magnetometer G-856AX and GPS. The distance between each stations is $2 \mathrm{Km}$ and 10 measurements and 10 measurements are taken at each station so that to have the mean. In the survey, we use the horizontal position of the magnetometer core.

\section{RESULT AND DISCUSSION}

Total magnetic intensity disturbances or anomalies are highly variable in shape and amplitude; they are almost always asymmetrical, sometimes appear complex even fro; simple sources and, usually portray the combined magnetic effects of several sources. Furthermore, there are an infinite number of possible sources which can produce a given anomaly. The apparent complexity of such anomalies is a consequence of the net effect of several independent but relatively simple functions however, and given some reasonable assumptions regarding the geology or whatever other source one is seeking to understand, a qualitative but satisfactory interpretation can usually be obtained for most anomaly source [5].

After compilation of these data, the contour magnetic map is represents by the Figure 3. 

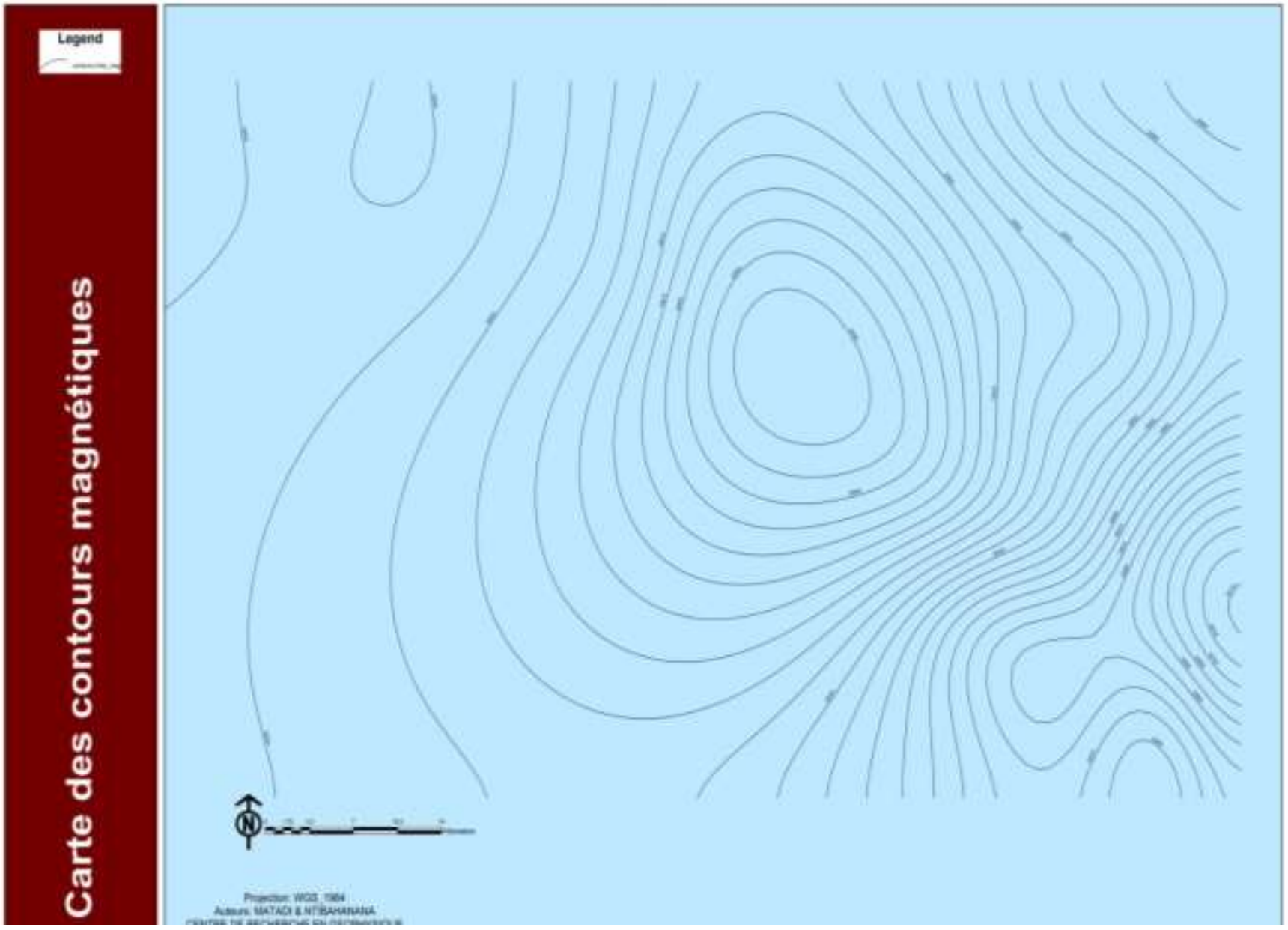

Figure 4: contour magnetic map

In this map, we can see cylindrical structure (especially the ellipses) and the discontinuity informations. The zones of magnetic anomalies and the folds zones show the intrusions mark caused the circular indications of magnetic rock, explaining the closed linear outline.

The change in the behavior of the magnetic field, it's showing the irregularities (Figure 5). 


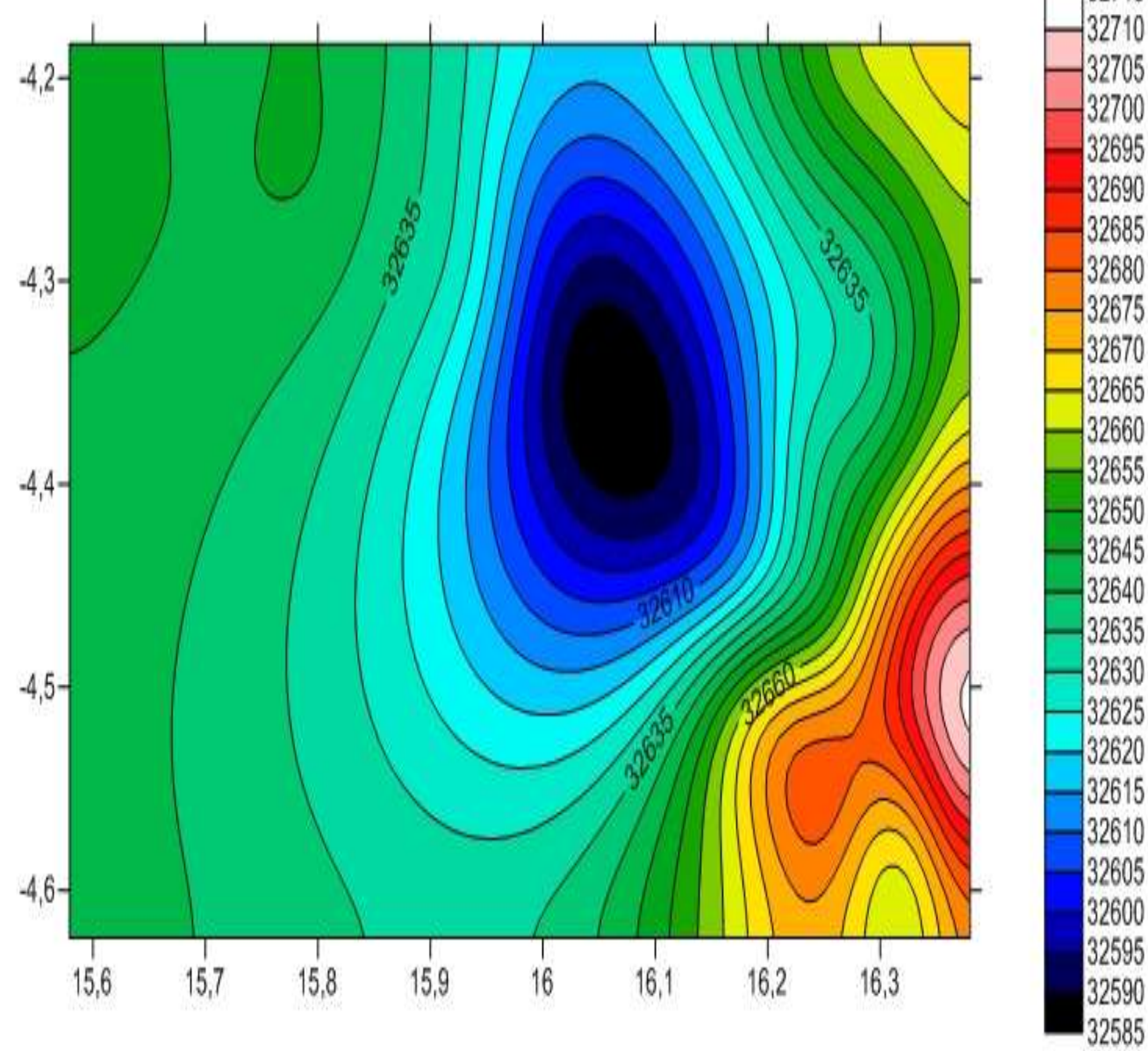

Figure 5: Anomalies magnetic map

The magnetic anomalies map presents a high anomaly, a low anomaly and the medium anomaly area. These anomalies are distributed as shown with increasing value to South area part and the anomaly located on the southwest area, shows the slight anomalies indicating a density discontinuity in subsoil [4].

These are linear anomalies and circular anomalies. There are also other trends such as the extension of iso-anomaly curves in a preferential direction, the alignment of minimum or maximum values and discontinuities in the regularity of these values. Looking at the same magnetic map of our study area (figure 9), we find that most anomalies are more or less circular and/or ellipsoidal. This situation is the expression of the presence of a very high gradient of the magnetic field towards the south-west of our study area. We remark the structural model shows the existence of several ditches probably corresponding to the maturation areas of the source rocks[6] 

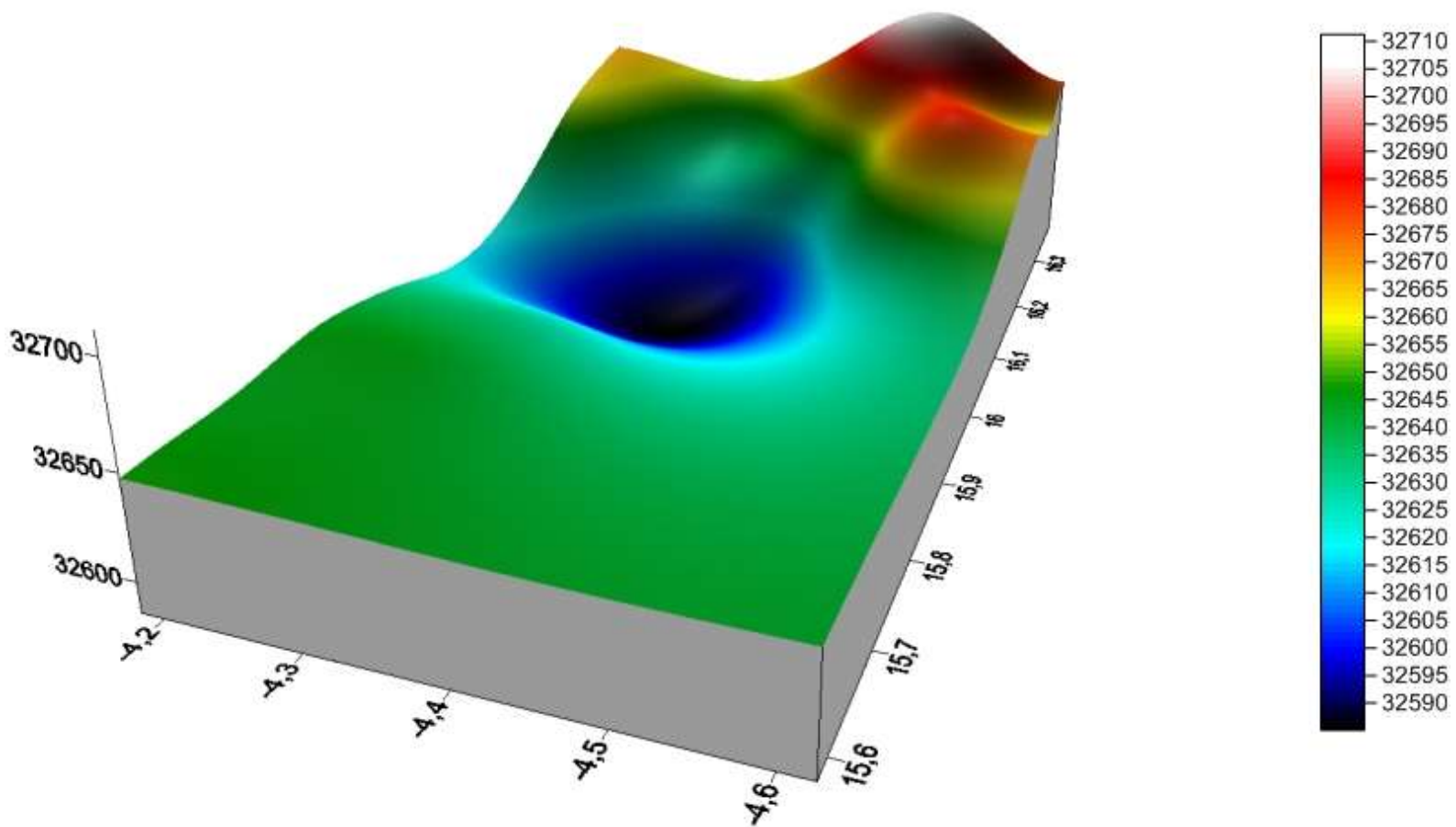

Figure 6: the 3D magnetic anomalies distribution

The Figure 5 and the Figure 6 show that the very low value of the total magnetic field intensity.

Another significant characteristic of a magnetic anomaly is its variation with the depth between the magnetometer and source, the deeper the source, the broader the anomaly as expressed in Figure 7.It is the property which enables one to determine the approximate depth to the source independent of any other information concerning the source, it should be the general characteristics of anomaly wavelength, or width, as a function of depth.

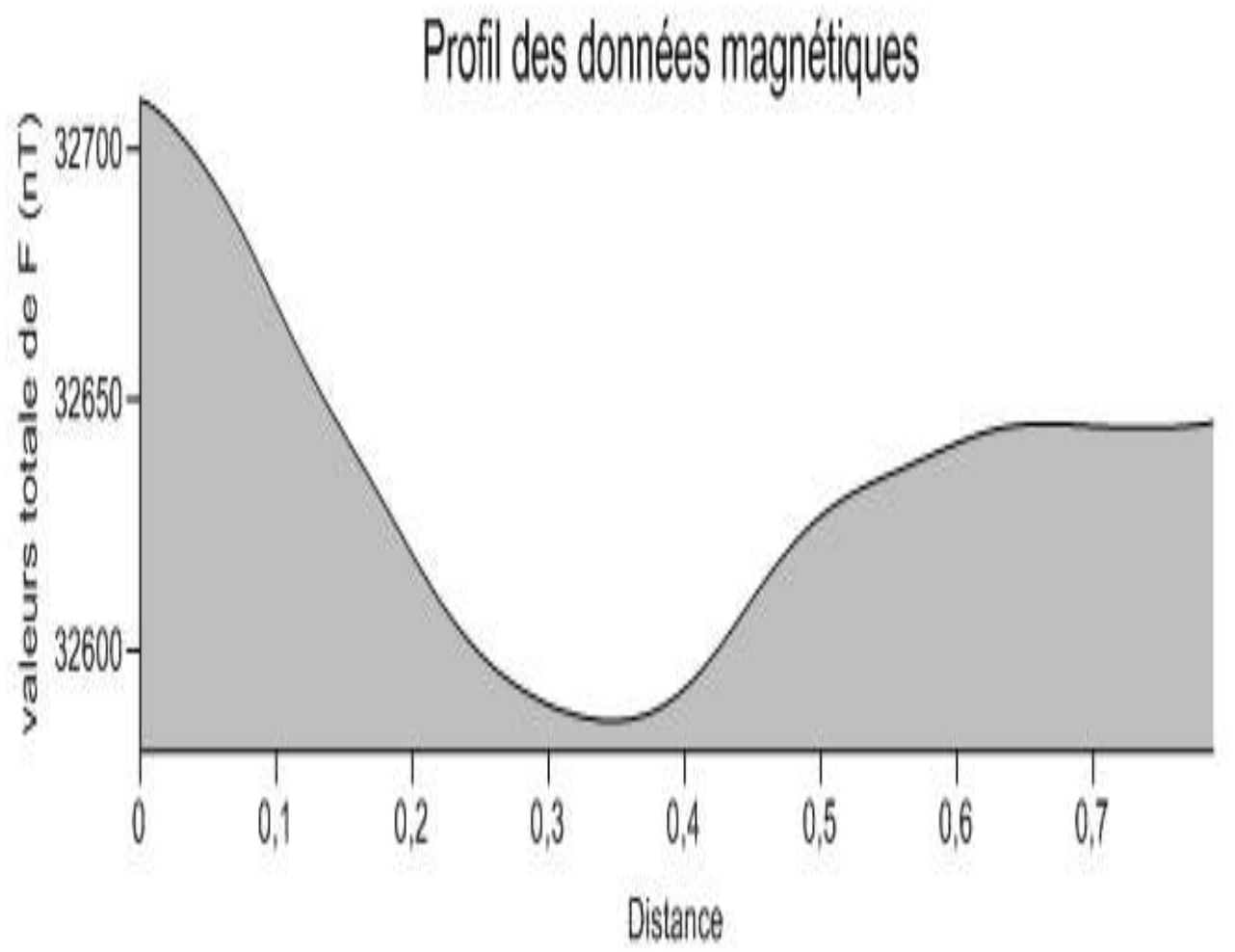

Figure 7: Total magnetic field intensity profile 
The approximate geological model of this profile is a sphere, it's showing the apparent depth variation of the total magnetic field intensity [1].

\section{CONCLUSION}

This study has allowed the elaboration of magnetic maps in Bateke plateau-Mongata underlining the anomalies spatial distribution and analysis of the maps has showed the magnetic anomalies apparent structure in this area.

The geological structure presents the regularity and geomagnetic distribution shows some irregularities associated to the depth.

The obtained data indicated meanwhile the apparent geological uniformity of the Bateke plateau and these anomalies correspond to an average total magnetic field intensity of 32658,5952 nT.

The differents maps show also the high magnetic gradient zone indicating the presence in the subsoil of density discontinuities due to some structures such as the intrusive rocks and note that the total magnetic mean field obtained in the Bateke plateau is quite similar to the mean value obtained in Binza magnetic observatory.

\section{REFERENCES}

[1] Cyril L., "Mini manuel de Géologie-géophysique”, édition Dunod, Paris, France,2011, pp 40-43

[2] Breiner S. "Applications manual for portable magnetometers", geometrics, California, USA,1999,pp 112-121

[3] Mbuangi M., "Monographie de la ville de Kinshasa,Comité Provincial de la Stratégie pour la Réduction de la Pauvreté de la Ville-Province de Kinshasa”,Document Inédit,Kinshasa,R.D.CONGO,1998

[4] Tondozi K., Zana N., Mukala K. et Mukandila N. "Inversion des anomalies gravimétriques de la région de Virunga", Revue Congolaise des Sciences, Volume n ${ }^{\circ}$, édition Conseil Scientifique National, R.D. Congo, 2012, pp 21-28

[5] Jacques D., Michel D., Pascal J.C., "Géophysique cours et exercices corrigés", 4ème édition Dunod, Paris.

[6] Tondozi and alt, " Interpretation of Magnetic Data for the Determination of Geological Structures in Southern Part of the Cuvette-Centrale Sedimentary Basin", International Journal of Advances in Scientific Research and Engineering (ijasre), Volume 6, Issue 2 February - 2020, pp145-155 